\title{
Влияние инвестиционного климата в регионах на развитие облигационного рынка
}

\author{
Н.В. АНОХИН, кандидат экономических наук, Сибирский филиал ПАО \\ Московская Биржа, Новосибирск. E-mail: nv-an@bk.ru \\ В.А. КАРАВАEB, кандидат экономических наук, Сибирский филиал ПАО \\ Московская Биржа, Новосибирск. E-mail: Vasiliy.Karavaev@moex.com \\ C.Е. КОЛБИН, кандидат технических наук, Сибирский филиал ПАО \\ Московская Биржа, Новосибирск. E-mail: Sergey.Kolbin@moex.com \\ Н.Г. ПРОТАС, кандидат экономических наук, \\ Новосибирский государственный университет экономики и управления \\ «НИНХ», Новосибирск. E-mail: n.protas@mail.ru
}

В статье рассматриваются методические подходы к получению количественных оценок влияния факторов качества инвестиционного климата на реализацию потенциала регионального рынка облигаций и возможности его роста в разрезе федеральных округов РФ. Описывается построение математической модели динамики облигационного рынка, включающей параметры влияния факторов инвестиционного климата на реализацию инвестиционного потенциала регионов. Приводятся количественные оценки параметров влияния инвестиционного климата, полученные на основе региональных рейтингов ведущих российских аналитических экспертных агентств. Представлены оценки динамики облигационного рынка в региональном разрезе на основе проведенных модельных расчетов. Сделаны выводы о возможности роста объемов облигационного рынка в РФ, а также о необходимых для этого мерах.

Ключевые слова: облигации, потенциал рынка в региональном разрезе, привлечение инвестиций, инвестиционный климат

В условиях наступившего оживления в экономике РФ возрастает потребность бизнеса в расширении источников привлечения инвестиционных ресурсов для развития производства. При этом развивается только один канал перераспределения ресурсов - через банковский вклад и кредит. Возможный альтернативный источник инвестиций - рынок публичного заемного капитала через выпуск облигаций - до последнего времени был в РФ слабо развит (например, см. [Балакирев, Давиденко, 2008]), что существенно ограничивает возможности наращивания инвестиций корпорациями. В особенности это касается региональных компаний среднего уровня.

Из-за сложного положения дел российский банковский сектор сосредоточил кредитование на крупном бизнесе, а кредиты для 
среднего и малого бизнеса недоступны или выдаются по завышенным ставкам. Рынок же публичных заимствований по сути своей более открытый и демократичный, к нему привлечено внимание широкого круга инвесторов, что позволяет снизить стоимость займов в сравнении с банковским кредитом. Это подтверждается обширным мировым опытом развития рынка облигаций (например, см. [Фабоцци, 2007; Фабоцци, Уилсон, 2016]).

В статье «Региональный рынок облигаций - штиль перед штормом?» [Анохин и др., 2017] авторами были представлены результаты исследования потенциала развития рынка облигаций как важнейшего сегмента финансового рынка Российской Федерации, а также количественные оценки его объема в разрезе федеральных округов РФ по данным за 2015 г.

Была показана сильная дифференциация уровня фактической реализации потенциала развития облигационного рынка в макрорегионах РФ. Отмечалось, что степень использования облигационных займов как инструмента публичных заимствований для корпоративного и государственного секторов в регионах во многом определяется качеством инвестиционного климата и бизнес-среды.

Диапазон качественных факторов инвестиционного климата в регионах достаточно велик: от уровня финансовой грамотности населения и специалистов во властных структурах и корпорациях, их информированности в использовании инструментов облигационного рынка до развитости местного законодательства, инвестиционных институтов и инфраструктуры. Некоторые из этих факторов можно определить количественно, но большинство носят качественный характер и могут быть оценены только путем сравнительных экспертных оценок, проведения специальных обследований и опросов аналитическими и рейтинговыми агентствами, составляющими рейтинги субъектов РФ по состоянию инвестиционного климата и инвестиционной привлекательности.

С точки зрения исследования развития рынка облигаций представляет интерес возможность получения количественной прогнозной оценки влияния «тонкой материи»- факторов, качественно характеризующих инвестиционный климат и инвестиционную привлекательность регионов, на динамику регионального облигационного рынка и степень реализации его потенциала.
В этой связи нами была предпринята попытка построения математической модели развития облигационного рынка в макрорегионах РФ, включающей количественную компоненту влияния факторов регионального инвестиционного климата. Проведены расчеты с целью получения прогнозных оценок объемов облигационного долга в макрорегионах РФ в трехлетней перспективе. Количественные компоненты оценки влияния состояния инвестиционного климата и бизнес-среды в регионах на развитие облигационного рынка рассчитывались нами на основе качественных оценок рейтингов субъектов РФ в 2015 г., построенных наиболее авторитетными российскими рейтинговыми агентствами (рейтинги состояния инвестиционного климата в субъектах РФ Агентства стратегических инициатив (АСИ) и индексы инвестиционных рисков, характеризующих инвестиционный и бизнес-климат в субъектах РФ, рейтингового агентства «Эксперт РА»).

\section{Оценка на основе национального рейтинга состояния инвестиционного климата в субъектах РФ (по методике АСИ)}

Данный рейтинг ${ }^{1}$ оценивает усилия региональных властей по созданию благоприятных условий ведения бизнеса и выявляет лучшие практики. Рейтинг субъектов РФ оценивается по 45 показателям, характеризующим 17 факторов, составляющих четыре направления:

1) регуляторная среда;

2) институты для бизнеса;

3) инфраструктура и ресурсы;

4) поддержка малого предпринимательства.

Подавляющее большинство показателей для оценки рейтинга оцениваются экспертным путем с применением социологических методов: экспертной оценки, опроса предпринимателей и инвесторов (генеральная и специальные генеральные совокупности). Все оценки представлены в баллах по стандартной шкале.

В зависимости от уровня интегральной оценки рейтинга по направлениям регионы объединены в пять групп - с I по V, в порядке убывания оценки рейтинга. За 2015 г. рейтинговые оценки получили

${ }^{1}$ Агентство стратегических инициатив (АСИ). URL: http://asi.ru/investclimate/rating (дата обращения: 22.08.2017). 
76 субъектов РФ из 85. Для дальнейшего анализа по федеральным округам небольшие периферийные регионы, не получившие рейтинговой оценки, мы условно отнесем к V группе. В результате в группу I вошли пять регионов, группу II - 24, III - 21, IV - 19, в группу $\mathrm{V}$ - семь (и еще девять регионов, не получивших оценки). Если перейти к балльной системе оценки рейтинга (номер группы дает соответствующее количество баллов) и сгруппировать регионы по федеральным округам, то для каждого округа можно вычислить рейтинг в баллах как среднюю величину от оценок входящих в него регионов. Чем ниже будет оценка в баллах, тем выше рейтинг состояния инвестиционного климата в федеральном округе.

Далее для понимания общей взаимосвязи между оценками рейтинга состояния инвестиционного климата в федеральных округах РФ и динамикой использования в них инструментов облигационных заимствований было проведено сопоставление оценок рейтингов АСИ в 2015 г. с динамикой размещения облигаций за 2016 г. - первое полугодие 2017 г. по отношению к 2015 г. (табл. 1).

Таблица 1. Расчет рейтинга федеральных округов на основе оценки рейтинга инвестиционного климата АСИ и динамики размещения облигаций по данным Небанковской кредитной организации АО «Национальный расчетный депозитарий" (НКО АО НРД) в 2015-2017 гг.

\begin{tabular}{|c|c|c|c|c|c|c|}
\hline \multirow{2}{*}{$\begin{array}{l}\text { Федеральный } \\
\text { округ }\end{array}$} & \multirow{2}{*}{$\begin{array}{c}\text { Оценка Ф0 } \\
\text { по среднему } \\
\text { баллу входя- } \\
\text { щих в него } \\
\text { субъектов РФ } \\
\text { в рейтинге } \\
\end{array}$} & \multirow{2}{*}{$\begin{array}{c}\text { Рэнкинг } \\
\text { ФО по ве- } \\
\text { личине } \\
\text { рейтинга } \\
\text { АСИ }\end{array}$} & \multicolumn{2}{|c|}{$\begin{array}{l}\text { Объем размещенных } \\
\text { облигаций, млн руб. }\end{array}$} & \multirow{2}{*}{$\begin{array}{c}\text { При- } \\
\text { рост, } \\
\%\end{array}$} & \multirow{2}{*}{$\begin{array}{c}\text { Прирост } \\
\text { в средне-- } \\
\text { годовой } \\
\text { оценке,\% }\end{array}$} \\
\hline & & & 2015 & $\begin{array}{l}2016 \text { г.- } \\
\text { 1-е полуго- } \\
\text { дие } 2017\end{array}$ & & \\
\hline Центральный & 2,44 & 1 & 1730772,21 & 2899303,31 & 67,52 & 45,01 \\
\hline $\begin{array}{l}\text { Северо- } \\
\text { Западный }\end{array}$ & 3,36 & 4 & 134789,80 & 216368,96 & 60,52 & 40,35 \\
\hline Южный & 3,75 & 5 & 71865,00 & 47114,07 & $-34,44$ & $-22,96$ \\
\hline $\begin{array}{l}\text { Северо- } \\
\text { Кавказский }\end{array}$ & 4,14 & 8 & 10000,00 & 6150,00 & $-38,50$ & $-25,67$ \\
\hline Приволжский & 2,50 & $2-3$ & 78900,00 & 224650,00 & 184,73 & 123,15 \\
\hline Уральский & 2,50 & $2-3$ & 52150,86 & 144489,08 & 177,06 & 118,04 \\
\hline Сибирский & 3,83 & 6 & 58505,10 & 100011,00 & 70,94 & 47,29 \\
\hline Дальневосточный & 4,00 & 7 & 6000,00 & 11100,00 & 85,00 & 56,67 \\
\hline Всего по РФ & 3,20 & & 2142982,97 & 3649186,42 & 70,29 & 46,86 \\
\hline
\end{tabular}

Источник табл 1, 4: Небанковская кредитная организация акционерное общество «Национальный расчетный депозитарий» (НКО АO HРД). URL: https://www. nsd.ru/ru/ (дата обращения: 25.07.2017).
Данные таблицы свидетельствуют о том, что лидерами по рейтингу состояния инвестиционного климата, рассчитанного на основе оценок АСИ, являются Центральный (далее ЦФО), Приволжский (ПФО) и Уральский (УФО) (в табл. 1 выделены жирным шрифтом). В этих округах средний темп прироста объема размещения облигаций за 2016 г. - первое полугодие 2017 г. по отношению к уровню 2015 г. в среднегодовом выражении составил 95,4\% при среднем по РФ темпе прироста 46,86\% (превышение среднероссийского показателя - более чем вдвое). По остальным пяти федеральным округам с рейтингом ниже общероссийского темп прироста в среднегодовом выражении составил 19,14\% (почти в пять раз ниже, чем у округов-лидеров).

Темпы роста объемов размещения облигаций в целом по РФ, а также для групп федеральных округов с высоким и низким рейтингами состояния инвестиционного климата представлены на рисунке 1 .

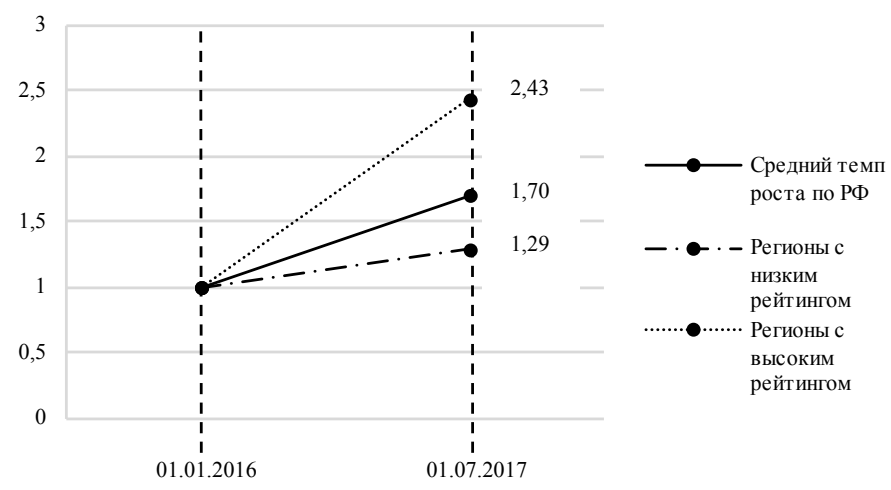

Рис. 1. Темп роста объемов размещения облигаций с 01.01.2016 г. по 01.07.2017 в регионах с низким и высоким рейтингом инвестиционного климата (по оценке АСИ), доли единицы

Таким образом, можно сделать вывод о наличии положительной связи между оценкой состояния инвестиционного климата в регионах и динамикой развития рынка облигаций.

Для получения прогнозов развития облигационного рынка в регионах в зависимости от рассчитанных оценок состояния в них 
инвестиционного климата нами были рассчитаны коэффициенты, количественно отражающие влияние состояния инвестиционного климата на степень реализации регионального потенциала рынка облигаций, оценки которого были получены на предыдущих этапах исследования (табл. 2).

Таблица 2. Коэффициенты, количественно отражающие влияние состояния инвестиционного климата на степень реализации регионального потенциала рынка облигаций (на основе оценок АСИ)

\begin{tabular}{|l|c|c|c|}
\hline $\begin{array}{c}\text { Федеральный } \\
\text { округ }\end{array}$ & $\begin{array}{c}\text { Рейтинг состояния инвести- } \\
\text { ционного климата, баллов }\end{array}$ & Рэнкинг & $\begin{array}{c}\text { Коэффициент влияния } \\
\text { инвестиционного климата }\end{array}$ \\
\hline Центральный & 2,44 & 1 & 0,6400 \\
\hline Северо-Западный & 3,36 & 4 & 0,4100 \\
\hline Южный & 3,75 & 5 & 0,3125 \\
\hline Северо-Кавказский & 4,14 & 8 & 0,2150 \\
\hline Приволжский & 2,50 & $2-3$ & 0,6250 \\
\hline Уральский & 2,50 & $2-3$ & 0,6250 \\
\hline Сибирский & 3,83 & 6 & 0,2925 \\
\hline Дальневосточный & 4,00 & 7 & 0,2500 \\
\hline По РФ в среднем & $\mathbf{3 , 2 0}$ & & $\mathbf{0 , 4 5 0 0}$ \\
\hline
\end{tabular}

В последнем столбце таблицы 2 представлены полученные нами количественные оценки коэффициентов влияния инвестиционного климата регионов в шкале от 0 до 1 из предположения, что для регионов, входящих в высшую, I группу рейтинга АСИ, значение коэффициента равно 1 , а для регионов последней, $\mathrm{V}$ группы, - 0. Интервал шкалы количественной оценки коэффициентов может быть изменен с учетом дальнейшей верификации результатов получаемых прогнозных модельных расчетов.

\section{Оценка на основе рейтинга инвестиционной привлекательности регионов РФ (по методике «Эксперт РА»)}

Расчеты, аналогичные приведенным выше, можно провести на основе оценки индексов инвестиционных рисков, полученной агентством «Эксперт РА» в процессе составления рейтинга инвестиционной привлекательности регионов РФ². Инвестиционный риск - качественно-количественная характеристика, которая

\footnotetext{
${ }^{2}$ Рейтинговое агентство «Эксперт PA». URL: https://raexpert.ru/ratings/regions/ (дата обращения: 25.08.2017).
}

отражает инвестиционную привлекательность региона через некоммерческие риски среды, с которыми приходится сталкиваться предпринимателям в субъекте, а также общее состояние бизнеса в регионе. Инвестиционный риск субъекта складывается из шести частных рисков (каждый из которых характеризуется целой группой показателей-факторов): экономический, социальный, финансовый, управленческий, экологический, а также криминальный.

Индекс каждого из шести частных рисков региона рассчитывается по «минимаксному методу», когда субъект РФ с минимальным значением показателя риска получает значение индекса 0 , a с максимальным - 1 . Все остальные регионы имеют значения индексов пропорционально отношению их показателей к крайним значениям. Интегральный индекс инвестиционного риска каждого региона рассчитывается как средневзвешенная сумма частных индексов инвестиционных рисков.

На основе оценок интегральных индексов риска субъектов РФ в 2015 г. агентства «Эксперт РА» нами были рассчитаны агрегированные интегральные индексы инвестиционного риска для федеральных округов как средние величины от значений индексов входящих в них субъектов РФ (табл. 3).

\section{Таблица 3. Коэффициенты, количественно отражающие влияние Факторов состояния инвестиционного климата на степень реализации регионального потенциала рынка облигаций (по данным агентства “Эксперт РА»)}

\begin{tabular}{|l|c|c|c|}
\hline $\begin{array}{c}\text { Федеральный } \\
\text { округ }\end{array}$ & $\begin{array}{c}\text { Оценка интегрального индек- } \\
\text { са инвестиционного риска }\end{array}$ & Рэнкинг & $\begin{array}{c}\text { Коэффициент влияния } \\
\text { инвестиционного климата }\end{array}$ \\
\hline Центральный & 0,223 & 1 & 0,8211 \\
\hline Северо-Западный & 0,281 & 4 & 0,6789 \\
\hline Южный & 0,303 & 5 & 0,6250 \\
\hline Северо-Кавказский & 0,428 & 8 & 0,3186 \\
\hline Приволжский & 0,248 & 3 & 0,7592 \\
\hline Уральский & 0,246 & 2 & 0,7647 \\
\hline Сибирский & 0,317 & 6 & 0,5907 \\
\hline Дальневосточный & 0,328 & 7 & 0,5637 \\
\hline По РФ в среднем & $\mathbf{0 , 2 8 5}$ & & $\mathbf{0 , 6 6 9 1}$ \\
\hline
\end{tabular}

В последнем столбце таблицы представлены полученные нами количественные оценки коэффициентов влияния инвестиционного климата регионов в шкале от 0 до 1 , когда субъект РФ с минимальным интегральным индексом риска получает 
значение коэффициента «1», а с максимальным - 0. Все макрорегионы имеют значения коэффициентов в интервале от 0 до 1 пропорционально отношению их индексов к крайним значениям. Интервал шкалы количественной оценки компонент может быть изменен с учетом дальнейшей верификации результатов получаемых прогнозных модельных расчетов.

Обращает на себя внимание тот факт, что рэнкинги федеральных округов в таблицах 2 и 3 на основе данных рейтингов АСИ и «Эксперт РА» (а значит, и их рэнкинги по рассчитанным значениям компонент инвестиционного климата) полностью совпадают.

\section{Построение математической модели развития облигационного рынка в регионах и проведение расчетов прогнозных оценок его объема на конец 2018 г.}

Следует отметить, что тема влияния регионального инвестиционного климата на показатели инвестиционной активности в настоящее время совершенно не разработана, отсутствует представительная и однородная информационная база по большинству изучаемых показателей и региональных факторов развития рынка облигаций (например, рейтинги инвестиционного климата АСИ впервые, и то не для всех субъектов РФ, были получены только за 2015 г.). Это не дает возможности применения классических статистических методов количественной оценки зависимостей и взаимосвязей между этими показателями и факторами. Поэтому мы для своих оценок используем эвристические, а не формальные методы моделирования, основанные на определенных допущениях - на постулировании логических связей и зависимостей, оценке и конструировании ряда параметров модели эмпирическим путем и на базе непосредственного наблюдения количественных соотношений показателей процесса.

Для расчета прогнозных оценок объемов облигационного долга и их динамики по регионам РФ за 2016-2018 гг. по сравнению с принятым за базу 2015 г. с учетом полученных количественных параметров коэффициентов, характеризующих влияние состояния инвестиционного климата в регионах РФ на степень реализации потенциала развития рынка облигаций, была построена эвристическая математическая модель.
В качестве основного расчетного показателя в модели принят суммарный объем накопленного долга в размещенных корпоративных, субфедеральных и муниципальных облигациях региона на конец года $\mathrm{t}$ (в базовом 2015 г. $t=0$ ). Временной горизонт прогнозных модельных расчетов для получения количественных оценок показателя развития облигационного рынка, в котором параметры модели, оцененные по данным за 2015 г., сохраняют свою значимость, принимаем в три года (то есть расчеты могут проводиться для $t=1,2,3$ или с 2016 по 2018 гг.).

Формула для модельных расчетов прогнозных оценочных величин (показателей накопленного облигационного долга региона) имеет следующий вид:

$$
V_{r t}=\left(V_{\text {ro }}-V_{\text {ro }} \times 0,1 \times t\right)+\left(V_{y} \times D_{r} \times K_{r} \times t\right),
$$

где: $V_{r t}$ - расчетная оценка величины накопленного облигационного долга региона r на конец года $\mathrm{t}$;

0,1 - принятый на основе наших эмпирических оценок за 2015-2016 гг. коэффициент доли объема погашаемых (или выкупаемых) в течение года облигаций к накопленному объему облигационного долга на конец 2015 г.;

$V_{\text {ro }}$ - величина накопленного облигационного долга региона $r$ на конец 2015 г. по данным НКО АО НРД;

$V_{y}$ - полученная оценка величины потенциала годового объема размещения корпоративных, субфедеральных и муниципальных облигаций в РФ [Анохин, 2017] (интервал от 3,5 до 5 трлн руб.);

$D_{r}$ - доля региона $r$ в общей по РФ величине потенциала годового размещения облигаций;

$K_{r}$ - коэффициент влияния инвестиционного климата в регионе $r$, полученный на основе балльных количественных оценок состояния в регионах инвестиционного климата по данным рейтинга АСИ или оценок индексов инвестиционных рисков «Эксперт РА».

С помощью предложенной эвристической модели была проведена серия вариантных расчетов прогнозной оценки показателя накопленного облигационного долга по федеральным округам РФ на конец 2018 г., согласно которым предполагается реализация следующих сценариев развития рынка облигаций, в соответствии с оценкой годового потенциала размещения корпоративных, субфедеральных и муниципальных облигаций в регионах РФ.

Вариант № 1 - на уровне нижней оценки, равной 3,5 трлн руб. (коэффициенты влияния инвестиционного климата - на основе рейтинговых оценок АСИ).

Вариант № 2 - на уровне верхней оценки, равной 5 трлн руб. (коэффициенты влияния инвестиционного климата как в варианте № 1).

${ }^{3}$ URL: https://www.nsd.ru/ru (дата обращения: 25.07.2017). 
Вариант № 3 - на уровне нижней оценки, равной 3,5 трлн руб. (коэффициенты влияния инвестиционного климата - на основе региональных оценок инвестиционных рисков «Эксперт РА»).

Вариант № 4 - на уровне верхней оценки, равной 5 трлн руб. (коэффициенты влияния инвестиционного климата - как в варианте № 3).

Во всех четырех вариантах в качестве значений долей регионов в общей по РФ величине потенциала годового размещения облигаций $\left(D_{r}\right)$ использовались расчетные оценки для макрорегионов на основе рейтинга инвестиционного потенциала субъектов РФ за 2015 г. агентства «Эксперт РА» ${ }^{4}$.

Предварительно для верификации в первом приближении получаемых результатов модельных расчетов с имеющимися фактическими данными накопленного долга по региональным облигациям на конец 2016 г. по РФ в целом мы провели оценочные модельные расчеты по описанным выше четырем вариантам на 2016 г. (табл. 4).

Таблица 4. Результаты модельных расчетов прогнозных оценок
показателя накопленного облигационного долга
по вариантам прогнозов и сравнение с Фактическими
данными на конец 2016 г., млрд руб.
\begin{tabular}{|l|c|c|c|c|c|c|c|}
\hline $\begin{array}{l}\text { Федераль- } \\
\text { ный округ }\end{array}$ & $\begin{array}{c}\text { Вариант } \\
\text { № } 1\end{array}$ & $\begin{array}{c}\text { Вариант } \\
\text { № } 2\end{array}$ & $\begin{array}{c}\text { Вариант } \\
\text { № 3 }\end{array}$ & $\begin{array}{c}\text { Вариант } \\
\text { № 4 }\end{array}$ & $\begin{array}{c}\text { Средняя } \\
\text { оценка }\end{array}$ & $\begin{array}{c}\text { Факт } \\
\text { на конец } \\
\mathbf{2 0 1 6} \text { г. }\end{array}$ & $\begin{array}{c}\text { Отклонение } \\
\text { от средней } \\
\text { оценки, \% }\end{array}$ \\
\hline Всего по РФ & 8875 & 9642 & 9550 & 10645 & 9678 & 9584 & 1,00 \\
\hline
\end{tabular}

Из таблицы видно, что прогнозные оценки долга по региональным облигациям на конец 2016 г. по разным вариантам находятся в интервале 8875-10645 млрд руб. при средней величине 9678 млрд руб. Отклонение средней расчетной оценки от фактического значения объема накопленного долга по региональным облигациям - 9584 млрд руб. - не выходит за пределы $1 \%$, что вполне приемлемо, учитывая фактический прирост этого показателя за год - более $18 \%$.

Далее были проведены прогнозные модельные расчеты по четырем описанным сценарным вариантам для федеральных округов РФ на конец 2018 г. (табл. 5).

\footnotetext{
${ }^{4}$ Рейтинговое агентство «Эксперт PA». URL: https://raexpert.ru/ratings/regions/ (дата обращения: 25.08.2017).
}

Таблица 5. Результаты модельных расчетов прогнозных оценок показателя накопленного облигационного долга по вариантам прогнозов, млрд руб.

\begin{tabular}{|l|c|c|c|c|c|c|}
\hline $\begin{array}{c}\text { Федеральный } \\
\text { округ }\end{array}$ & $\begin{array}{c}\text { Вариант } \\
\text { № 1 }\end{array}$ & $\begin{array}{c}\text { Вариант } \\
\text { № 2 }\end{array}$ & $\begin{array}{c}\text { Вариант } \\
\text { № 3 }\end{array}$ & $\begin{array}{c}\text { Вариант } \\
\text { № 4 }\end{array}$ & $\begin{array}{c}\text { Средняя } \\
\text { оценка }\end{array}$ & $\begin{array}{c}\text { Доля в РФ } \\
\text { по средней } \\
\text { оценке,\% }\end{array}$ \\
\hline Центральный & 6811 & 7758 & 7436 & 8651 & 7664 & 57,25 \\
\hline Северо-Западный & 859 & 1066 & 1175 & 1518 & 1154 & 8,62 \\
\hline Южный & 396 & 514 & 673 & 910 & 623 & 4,66 \\
\hline Северо-Кавказский & 113 & 155 & 160 & 223 & 163 & 1,22 \\
\hline Приволжский & 1345 & 1813 & 1579 & 2147 & 1721 & 12,85 \\
\hline Уральский & 684 & 931 & 813 & 1114 & 885 & 6,61 \\
\hline Сибирский & 546 & 702 & 918 & 1234 & 850 & 6,35 \\
\hline Дальневосточный & 177 & 243 & 369 & 517 & 326 & 2,44 \\
\hline Всего по РФ & $\mathbf{1 0 9 3 1}$ & $\mathbf{1 3 1 8 2}$ & $\mathbf{1 3 1 2 3}$ & $\mathbf{1 6 3 1 4}$ & $\mathbf{1 3 3 8 6}$ & $\mathbf{1 0 0 , 0 0}$ \\
\hline
\end{tabular}

Согласно результатам представленных в таблице модельных расчетов по вариантам прогнозов, ожидается рост объема накопленного облигационного долга в РФ от уровня значения в 8111141 млн руб. на конец 2015 г. до уровня в интервале от 10931 млрд руб. (на 35\%) по варианту № 1 до 16314 млрд руб. по варианту № 4 (в 2,01 раза) на конец 2018 г. Средняя оценка четырех прогнозных вариантов - 13386 млрд руб., что соответствует росту накопленного долга за три года в 1,65 раза. При этом дифференциация долей федеральных округов в объеме долга по РФ сглаживается, в частности, доля абсолютного лидера Центрального ФО - снижается с $80 \%$ до $57 \%$.

\section{Выводы}

В последнее время со стороны федеральной власти РФ, Банка России и инфраструктурных институтов рынка ценных бумаг принимаются законодательные, нормативные и организационные меры для стимулирования развития рынка облигаций в РФ, направленные на уменьшение времени и снижение издержек у эмитентов при выходе на рынок публичных заимствований, а также повышение доходности и надежности вложений частных инвесторов в облигации. Однако, по мнению экспертов и инвесторов, ключевую роль в создании условий для выхода региональных компаний на облигационный рынок играют усилия региональных органов власти по улучшению инвестиционного климата - формированию региональных институтов и качества 
деловой среды для успешной конкуренции за привлечение инвестиций в регион.

Сопоставление рейтинговых оценок состояния инвестиционного климата в регионах с динамикой развития в них рынка облигаций по результатам наших расчетов показывает тенденцию положительной связи между рейтингом и темпом роста облигационного рынка.

Из полученных результатов модельных расчетов видно, что средняя прогнозная оценка показателя накопленного облигационного долга по РФ близка к нижней границе интервала величины потенциала привлечения инвестиций через размещение облигаций, оцененного нами (см. [Анохин и др., 2017]) в пределах от 13 до 20 трлн руб. Этот факт, очевидно, связан с влиянием качественных факторов инвестиционного климата в регионах через включение в модель для расчетов коэффициента влияния инвестиционного климата. Он иллюстрирует недостаточность усилий властных структур, контрольно-надзорных органов, отраслевых ассоциаций, профессиональных саморегулируемых организаций и, в особенности, региональных органов власти по формированию благоприятной инвестиционной среды, что особенно актуально для «отстающих» в этом отношении регионов РФ. Усиление внимания к улучшению этих факторов позволит снизить дифференциацию регионов по степени реализации в них потенциала развития рынка облигаций.

Ориентация на качественные факторы готовности и привлекательности регионов для привлечения инвестиций через облигационные займы предполагает дальнейшее более глубокое изучение, детальный анализ и корректировку их воздействия на рынок облигаций на уровне субъектов РФ с привлечением региональных институтов и агентов инвестиционного процесса.

\section{Литература}

Анохин Н. В. О некоторых подходах к оценке потенциала облигационного рынка макрорегионов России. // Вестник НГУЭУ. 2017. № 4. С. 108-124

Анохин Н.В., Караваев В.А., Колбин С.Е., Протас Н.Г. Региональный рынок облигаций - штиль перед штормом? // ЭКО. 2017. № 11. С. 177-190.

Балакирев Н.Н., Давиденко Л.П. Облигации в системе рыночных отношений Российской Федерации. Санкт-Петербург: ИВЭСЭП, Знание, 2008. 64 с.

Фабоции Ф. Дж. Рынок облигаций. Анализ и стратегии. М.: Альпина Бизнес Букс, 2007. 958 с.
Фабоици Ф. Дж., Уилсон Р. С. Корпоративные облигации. Структура и анализ. М.: Альпина Паблишер, 2016. 444 с.

Статья получена 19.12.2017.

\section{Summary}

Anokhin N.V., Siberian branch, OJSC Moscow Exchange, Novosibirsk, Karavaev V.A., Siberian branch, OJSC Moscow Exchange, Novosibirsk, Kolbin S.E. Siberian branch, OJSC Moscow Exchange, Novosibirsk, Protas N. G., Novosibirsk State University of Economics and Management, Novosibirsk

Considering Influence of the Investment Climate in the Regions on the Bond Market Development

The article considers the methodological approaches to obtaining quantitative estimates of the impact factors of the quality of the investment climate on the regional bond market reaching its maximum capacity and its possible growth in the context of the Federal districts of the Russian Federation. The article further describes the construction of a mathematical model for studying the dynamics of the bond market, including the parameters of the influence factors of the investment climate for reaching its potential investment capacity in the regions. Quantitative assessment of influence parameters of the investment climate are obtained on the basis of regional rankings of the leading Russian analytical expert agencies. The article also presents the evaluation of the dynamics of the bond market in the regional context on the basis of the model computations. The conclusions about the possibility of the growth of the bond market in the Russian Federation and about the necessary measures to support the growth are made.

Bond; the market potential in the regional context; attracting investment investment climate

\section{References}

Anohin N. V., Karavaev V.A., Kolbin S.E., Protas N. G. (2017). Regional'nyj rynok obligacij-shtil' pered shtormom? ECO. [ECO]. No 11. Pp. 177-190. (In Russ.)

Anohin N.V. (2017). O nekotoryh podhodah k ocenke potenciala obligacionnogo rynka makroregionov Rossii. Vestnik NGUEHU. No 4. Pp. 108-124. (In Russ.)

Balakirev N. N., Davidenko L.P. (2008). Obligacii v sisteme rynochnyh otnoshenij Rossijskoj Federacii. Sankt-Peterburg, IVEHSEHP, Znanie Publ. 64 p. (In Russ.)

Fabocci F. J. (2007). Rynok obligacij. Analiz i strategii. Moscow, Al'pina Biznes Buks Publ. 958 p. (In Russ.)

Fabocci F. J., Uilson R.S. (2016). Korporativnye obligacii. Struktura i analiz Moscow, Al'pina Pablisher. 444 p. (In Russ.) 